\title{
'Something else is possible': transcultural collaboration as anti-apartheid activism in the music of Juluka
}

\author{
CALEB MUTCH (1) \\ Max Planck Institute for Empirical Aesthetics, 376672 Frankfurt am Main, Germany \\ E-mail:cmm2209@columbia.edu
}

\begin{abstract}
This article illuminates the musical activism of Juluka, an interracial South African band active in the late 1970s through the mid-1980s. Its analyses of three songs focus on intersections between Western popular music and a Zulu song genre called maskanda. By examining these cross-cultural interactions in the domains of harmonic progressions, formal structures and metric and rhythmic organisation, I demonstrate that the artistic fruitfulness of the band's collaboration was a powerful rebuke to the government's apartheid ideology, which sought to segregate not just people, but even their artistic expressions.
\end{abstract}

It was the early years of the 1980s, and the South African band Juluka was on the wrong side of the law. Their music was banned from the airwaves, so they had to tour to gain audiences (Baines 2008, p. 107). Yet touring was not a simple prospect: they were restricted from performing in public venues, and travelling to outlying South African townships to perform meant breaking the law for half the band's members. When in rural areas, the band could finish about eighty percent of their performances without hindrance, but the other twenty percent saw the police using dogs and tear gas, and even bursting onto the stage carrying shotguns to declare the show over (Clegg 2017; Clegg and Drewett 2006, p. 130). How did the members of Juluka run afoul of what they called 'the wrong arm of the law' (Ngcobo 1982, p. 5)? They did so by presenting a potent challenge to apartheid ideology, in no small part by creating music whose artistic richness belies the principles of cultural segregation which the regime sought to uphold. To demonstrate this, this essay closely analyses compositional features in three songs by Juluka, showing how the band creatively combined Zulu and Western musical idioms to fashion a musical world where the two cultures flourishingly coexist.

\section{Preliminaries}

The apartheid regime's antagonist treatment of Juluka was not a reaction to any provocative activism. From the early 1970s onward the government banned albums on 
the grounds of indecency, blasphemy, disturbing peace, threatening the state and more (Drewett 2005, p. 55; Byerly 1998, p. 14). As a result, the members of Juluka addressed politics cautiously and did not mention apartheid. Yet their very existence as a group was a challenge to the apartheid regime of racial segregation, for half the band's members were white and the other half Zulu. Indeed, they did not need to criticise apartheid with words, for they embodied such a criticism: as Johnny Clegg, one of the co-founders, recounted, 'Juluka is the band that said on stage: "Something else is possible". That's all it said: "Something else is possible"" (Clegg 2017).

Juluka's origins lie in a transcultural friendship formed by Sipho Mchunu and Clegg. Mchunu (b. 1951) came from a rural Zulu family and was entirely unschooled, whereas Clegg (1953-2019) was born in Britain to white parents and for a time lectured in anthropology at a South African university. The two met in Johannesburg as teenagers, presumably at one of the migrant worker hotels Clegg surreptitiously visited to learn from Zulu dancers and musicians. They went on to form first a duo (called 'Sipho and Johnny') and then a band which they named Juluka, from the Zulu word for sweat (Meintjes 2017, pp. 155-6). ${ }^{1}$ While Juluka's embodiment of interracial cooperation was a very visible contradiction of the apartheid system, it was not the only reason why South African authorities repressed them. Like other South African 'activist-performers' (Eyerman and Jamison 1998, pp. 164-5), the members of Juluka mediated in a variety of ways the cultures which apartheid attempted to keep separate (Byerly 1998, pp. 1, 23-28). One approach was linguistic, as many of Juluka's songs use both English and Zulu lyrics. This combination of languages went against apartheid legislations seeking to keep languages 'pure', and it was consequently used as justification for the censorship of their first single, 'Woza Friday' (Clegg and Drewett 2006, p. 128). Another involved the band's live performances, where they sought to educate white audiences about the stories their songs told and the Zulu war dances they incorporated into performances. Even fans who only saw the band through their promotional material and albums' cover art still encountered that cultural mediation through the band's costumes, which prominently mixed Zulu and Western styles of dress. ${ }^{2}$

Of Juluka's many forms of cultural mediation, this essay focuses on the musical. Clegg himself has called explicit attention to this feature of their work: on his website's bio section, Clegg wrote that he 'worked on the concept of blending English lyrics and Western melodies with Zulu musical structures' with his songwriting partner, Mchunu (https://www.johnnyclegg.com/biog.html, accessed 2 March 2021). Despite this, scholarly treatments of Juluka have largely neglected analysing how these transcultural blendings are accomplished. ${ }^{3}$ Perhaps the most extended discussion of them, by Christopher Ballantine, is rather dismissive:

From the start the band's musical integrations were awkwardly worked. Certainly, symbols for 'white' and 'black' met in the songs' own interiors - but typically as binary, and often unequal, oppositions: 'white' represented largely by an English folk-rock style derived from the 1960s,

${ }^{1}$ For more biographical information on Clegg and Juluka see https://mg.co.za/article/2019-07-19-00johnny-clegg-in-retrospect-it-all-began-with-juluka/.

2 I thank one of my anonymous reviewers for flagging these non-musical aspects for my attention.

${ }^{3}$ The most sustained treatment of Juluka's transcultural compositional strategies I have encountered is by Ballantine, which is quoted anon. Meintjes (2017, pp. 156-7) and Muller (2008, pp. 115-17) go into significantly more analytic detail than Ballantine, but restrict their attention to Juluka's use of 'Zulu traditional sounds'. 
which carried the song's narrative, and 'black' virtually relegated to the choruses. The lyrics addressed topics relevant to the anti-apartheid struggle, but commonly in two languages (English and Zulu) split along the same lines. (Ballantine 2004, 109)

Perhaps unsurprisingly, Ballantine's hearing of Juluka's musical integrations as superficial is based on a listening experience that does not attend carefully to these songs' depth of artistry and ingenuity. As will be shown in this article, paying closer attention to their songs reveals that they exhibited a far more creative interplay of musical styles than Ballantine acknowledges.

The musical analyses which anchor the present article substantiate this claim. They attend to the blending of musical elements - textural, melodic, lyrical, harmonic, rhythmic and more - that symbolise 'white' and 'black'. In their catalogue of 70-odd commercially released songs, Juluka engage with a wide range of genres which signify 'white' and 'black', of which the most prominent are Western folk and rock music, and Zulu mbaqanga and maskanda music. The three songs selected for analysis were chosen in part because they draw especially on maskanda, ${ }^{4}$ a musical style whose harmonic and rhythmic characteristics are more readily distinguishable from Western styles than those of mbaqanga.

Maskanda music arose around the turn of the twentieth century among young Zulu men who migrated between their homes in rural South Africa and the centres of economic opportunity, such as mines and cities (Olsen 2014, pp. 20-25)..$^{5}$ In its original form, as preserved in recordings from the 1950s and earlier, maskanda featured a solo singer accompanying himself, most typically with a strummed guitar. ${ }^{6}$ In the following decades, however, a new style of guitar performance came to predominate, largely through the influence of the recordings of the maskanda icon Phuzushukela, the stage name of John Bengu (Olsen 2014, pp. 24-5, 32-3). In this style of fingerpicking, known as ukupika, guitarists use plectrums on their thumbs and forefingers to create two (or occasionally even three) simultaneous melodic lines (Collins 2006/ 2007, pp. 3-4). The resulting polyphonic effect is a hallmark of maskanda songs.

Starting in the early 1970s, producers at the South African Broadcasting Corporation ceased to record solo maskandi, as performers of maskanda are called, so the musicians formed accompanying groups (Davies 1994, p. 133). The resulting ensemble music still emphasised the guitar, however, and did so most prominently in the songs' introductions, which normally feature unaccompanied guitar. This introduction, called the isihlabo, is unmetred, and it serves to lay out the harmonic material for the rest of the song. Once the isihlabo concludes, the guitar establishes

4 According to Pooley, 'umaskandi' most accurately reflects how practising musicians refer to the genre (2016, p. 7), whereas 'maskandi' is by far the Internet's most commonly used version of the term. The English-language literature on the subject, however, favours 'maskanda', so I will retain that term for consistency's sake.

5 As Collins noted, prior to 2006 maskanda had 'not been much emphasised in the scholarly literature' (2006/2007, p. 3), so the present account of maskanda necessarily relies on research conducted several decades after the period of interest to this article. Much of that research, however, does not clearly distinguish between more recent developments in maskanda and the practice of the late 1970s through mid-1990s, a time of relative stylistic stability which Collins calls the " Zulu-Traditional" period in mas$k a n d a^{\prime}$ (p. 21). Based on Collins's work, which does the most to identify changes in maskanda (pp. 22-3), it appears that the characterisations of maskanda style upon which the present study draws may apply better to the 'Zulu-Traditional' period than to the more diverse practice of the post-apartheid era.

6 Since about the 1950s, maskanda guitarists have altered the usual Western guitar tuning scheme, most often by tuning the highest string down a whole tone (Davies 1994, pp. 121-2). 
a new 'melodic-rhythmic pattern' which undergirds what follows (Collins 2006/2007, p. 4). Above it, the singer initiates a call-and-response texture known as the $u k u b i z a$ nokusabela (Titus 2013, p. 305). ${ }^{7}$ The responses to the soloist's calls may be provided by either one of the guitar lines or back-up singers in maskanda groups; in either case, they characteristically both enter after and overlap with the soloist's calls, and their points of melodic closure do not align (Titus 2013, pp. 295-8).

The harmonic organisation of maskanda music varies across its subtypes. According to Barbara Titus, the isiShameni subtype 'is quasi-diatonic in applying an ostinato progression of I-IV-V-I, also often heard in the more urban mbaqanga and isicathamiya genres' (Titus 2013, 291). More significant for this study is the isiZulu subtype, which harkens back to Zulu bow songs. In these, as David Rycroft (1975/1976) has detailed, a normally female singer accompanies herself by percussing the single, undivided string of the $u g u b h u$, a bow which is $1.5-2 \mathrm{~m}$ long and is attached to a gourd resonator. Performers on this seemingly simple instrument can produce complex musical effects: by pinching the string, the performer can produce a second pitch, a semitone higher than that of the open string, and by shifting the position of the resonator against the body, the performer selectively amplifies harmonics of each fundamental in order to create a secondary melody (pp. 58-62). Other bow songs were performed on the umakhweyana, a divided bow, which is reputed to have been imported from Mozambique (p. 58). This instrument's string yields two fundamentals a whole tone apart, and pinching the higher string segment can produce a third fundamental pitch a semitone higher (Davies 1994, p. 132). Maskandi who performed in the isiZulu style distilled these acoustic phenomena to their harmonic and melodic principles: two triads, a semitone or whole tone apart, and six-note scale. (Maskandi, however, frequently employ minor triads, which were unavailable on the ugubhu; Davies 1994, p. 132.) Rycroft has noted that in ugubhu songs, either the lower or higher fundamental pitch may predominate (Rycroft 1975/1976, pp. 65-6). Secondary literature on maskanda music has not focused on how composer-performers deploy these harmonic materials in their songs, but I have observed in isiZulu music a similar propensity to emphasise either the lower or higher fundamental pitch.

Before proceeding to the analyses of compositional decisions, it is important to address the matter of compositional attribution. Louise Meintjes explains that 'from a young age Clegg came to embody Zulu aesthetics and affective warriordom by apprenticing himself to musicians and dancers' (Meintjes 2017, p. 155). Clegg's process of learning Zulu culture via personal contact muddles such attributions, particularly when considering elements of Zulu musical practice. The majority of songs in Juluka's catalogue were published under Clegg's name (the remainder are attributed solely to Mchunu or to both jointly). ${ }^{8}$ Yet given Clegg's status as someone seeking entrance into Zulu culture, it is unlikely that he dictated all stylistic details to the Zulu members of the band, or that they made no contributions of their own to

7 Another optional section is the izibongo, which features rapidly spoken self-praise; it usually appears about two-thirds of the way through the piece, and then gives way to further repeats of the call-and-response texture (Olsen 2014, p. 23). Since Juluka does not employ izibongo sections, they are not addressed further here, but interested readers may wish to consult Rycroft (1962), Gunner (1990) and especially Pooley (2016).

${ }^{8}$ Of the three songs examined here, the second, 'Sky People', is credited to Mchunu and Clegg, while the latter two are credited to Clegg alone. 
their performances. Furthermore, the bulk of the musical details analysed in this paper fall outside of the bounds of the compositional details for which the composers could legally claim copyright, and instead are characteristics of the performance, which is credited to the band. ${ }^{9}$ Additionally, the band's later reception further complicates attributions to Clegg alone. After Juluka disbanded and Mchunu returned to farming in 1985, Clegg formed another group, which recorded under the name 'Johnny Clegg and Savuka'. ${ }^{10}$ As a result, some internet resources refer to the earlier band as 'Johnny Clegg and Juluka', and even 'Johnny Clegg and Juluka [feat. Sipho Mchunu]'. ${ }^{11}$ This suggestion of 'Clegg and supporting musicians' is clearly a distortion of the band's self-presentation as a partnership among equals, since all of its albums were issued under the name 'Juluka' and featured Clegg and Mchunu together on the cover illustrations. Consequently, I will attribute compositional decisions to Juluka as a group in order both to reflect Clegg's collaborative approach to learning Zulu culture and to avoid minimising the significance of the other band members.

\section{'December African Rain'}

When Ballantine wrote that Juluka's symbols for 'white' were 'represented largely by an English folk-rock style' and that symbols for 'black' were virtually relegated to the choruses (2004, p. 109), he may have been thinking of a song such as 'December African Rain', from Juluka's 1984 album Work for All. In this song, Clegg sings an image-laden narrative through the verse and pre-chorus, while the chorus includes ngoma-signifying 'vocable motives with strong backbeat pickups sung in repeated cycles by the backing vocalists' of the sort that were frequently used by Juluka and Savuka (Meintjes 2017, pp. 157, 160-1).

Upon closer inspection, however, the picture becomes much richer. Consider the backing vocalists: in addition to their vocables with 'strong backbeat pickups' in the chorus, they also contribute a prominent strong-beat-emphasising vocable motive to the texture which underlies the intro, verses and outro (see Example 1 for the beginning of the first verse). ${ }^{12}$ The song starts with the guitar and drums establishing a repeated melodic-rhythmic pattern, and beginning in $\mathrm{m} .3$ the two-part

9 I thank one of my anonymous reviewers for bringing this distinction to my attention.

10 For more on Savuka and Clegg's career post-Juluka, see R. Pithouse's obituary of Clegg (https://mg.co. za/article/2019-07-18-johnny-clegg-rebel-intellectual-musician/, accessed 28 May 2020).

11 Even Rhythm Safari, the label which holds the rights to seven of Juluka's eight albums, refers to the group as 'Johnny Clegg and Juluka' on their website (https://www.rhythmsafari.com.au/clegg-catalogue, accessed 13 September 2019). There is clearly work to be done unpacking the power and racial dynamics that undergird Juluka's recent reception, although it lies beyond the scope of this article.

12 All transcriptions are my own. This article transcribes select passages using Western notation in order to assist readers' evaluations of its analytical descriptions and arguments. Western notation does not do justice to all aspects of this music, of course, but Juluka's engagement with Western popular music renders the music more amenable to Western-style transcription than many other musics would be. (The presence of fretted guitars and synthesisers, for instance, means that the pitch content aligns with staff notation quite well). Whereas the 'fixed text for analysis' that results necessarily reflects my understanding of the music (Solis 2012, pp. 542-3), I hope that the sharpness of analytical claims which transcription supports will spur readers to engage more deeply with the music and even develop interpretations of their own. 
5
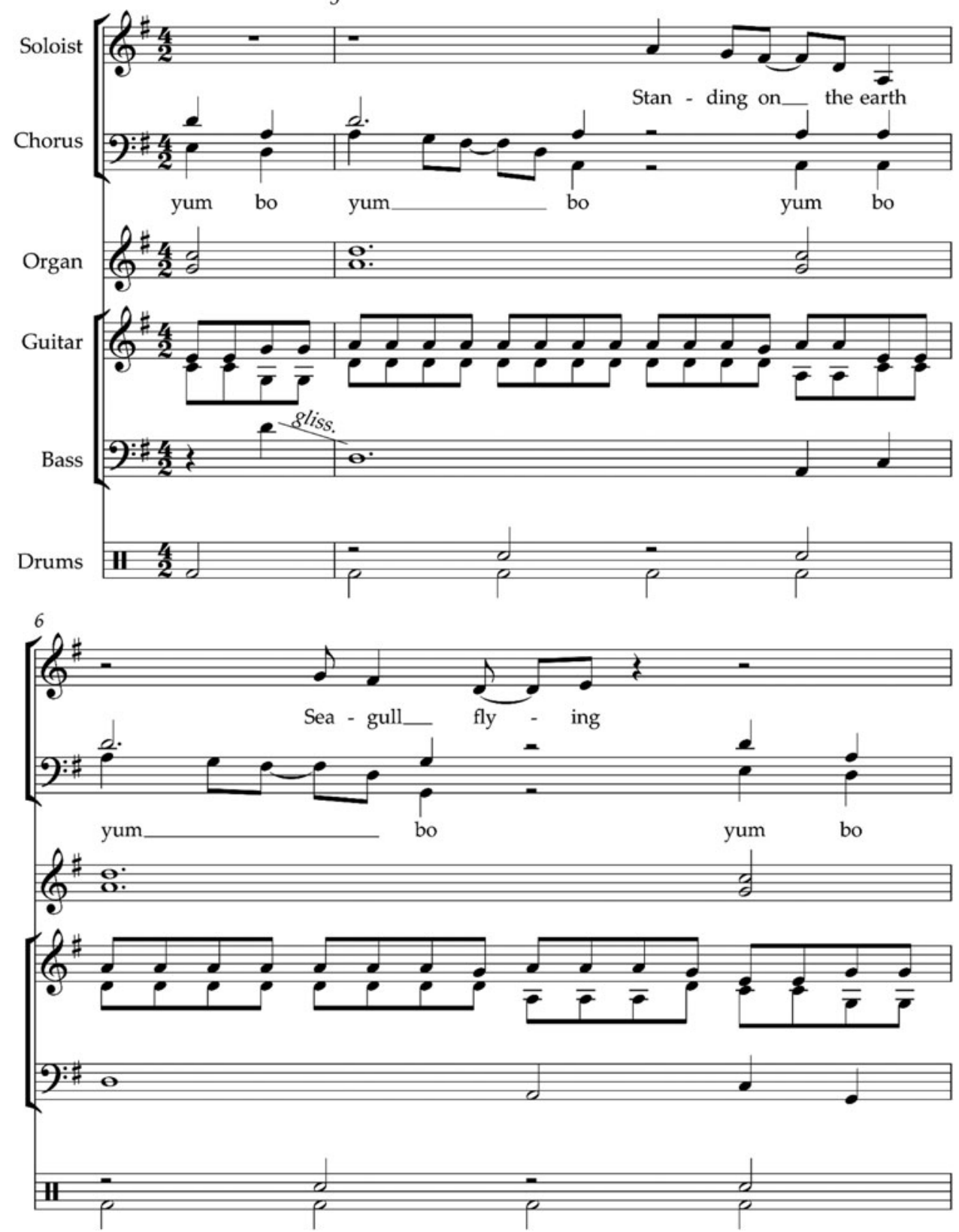

Example 1. Juluka, "December African Rain," beginning of verse.

chorus initiates a melodic descent every four beats and exactly repeats its melody every eight beats. Against this stable foundation the soloist enters partway through m. 5 with a call that echoes the lower chorus's melodic descent. The resulting call-and-response texture exhibits a non-alignment of calls and responses (with respect to both their entrances and points of arrival) that Rycroft describes as 
being paradigmatic for traditional music of both the Zulu people and their relatives, the Xhosa and Swazi (Rycroft 1977, p. 222). In this case, however, both the soloist and chorus begin their eight-beat-long melodies in the same measure, but the soloist's temporal relationship with the chorus shifts every four beats. In the first group of four beats, the soloist enters on the third crotchet, while the chorus is silent; in the second group, he enters on the second crotchet, overlapping with the chorus's invariant rhythm.

The hint of rhythmic instability that arises from the soloist's shifting relationship with the chorus starts to become unmistakable in $\mathrm{m}$. 11. There the soloist departs from the repeated two-measure phrase with a one-measure extension that combines the melodic descent of the phrase's first measure with the rhythmic disposition of the second measure. At $\mathrm{m}$. 12 the preceding music is disrupted by an abrupt change of texture and metre (see Example 2). As the chorus falls silent, the vocal texture shifts from call-and-response to a soloist-dominated texture in a lower tessitura. Simultaneously, the synthesiser drops out and the guitarist moves from playing dyads to a more arpeggiated texture. The metre changes even more notably. Until this point, the song has proceeded at a moderate pace, with duple groupings at every level of the musical structure, with the exception of the hypermetrical extension in m. 11. At m. 12 the drummer doubles the speed of his bass- and snare-drum pattern, which imparts an intensifying 'double-time' feeling to the new material. At the same time, the soloist, guitarist and bass player begin to establish a much more complex metre. The metrical organisation is clearly based on an 18-beat period: the melody introduced in $\mathrm{m} .12$ returns 18 beats later, at the start of m. 15, and then the chorus section begins 18 beats after that. Within those 18 beats, however, the organisation is more ambiguous. The rhythmic profile of the first 10 beats (m. 12) is particularly complex. Against the drum-set's steady crotchet pulse, the bass and soloist initially present a dotted-crotchet pulse, but this is contradicted at the
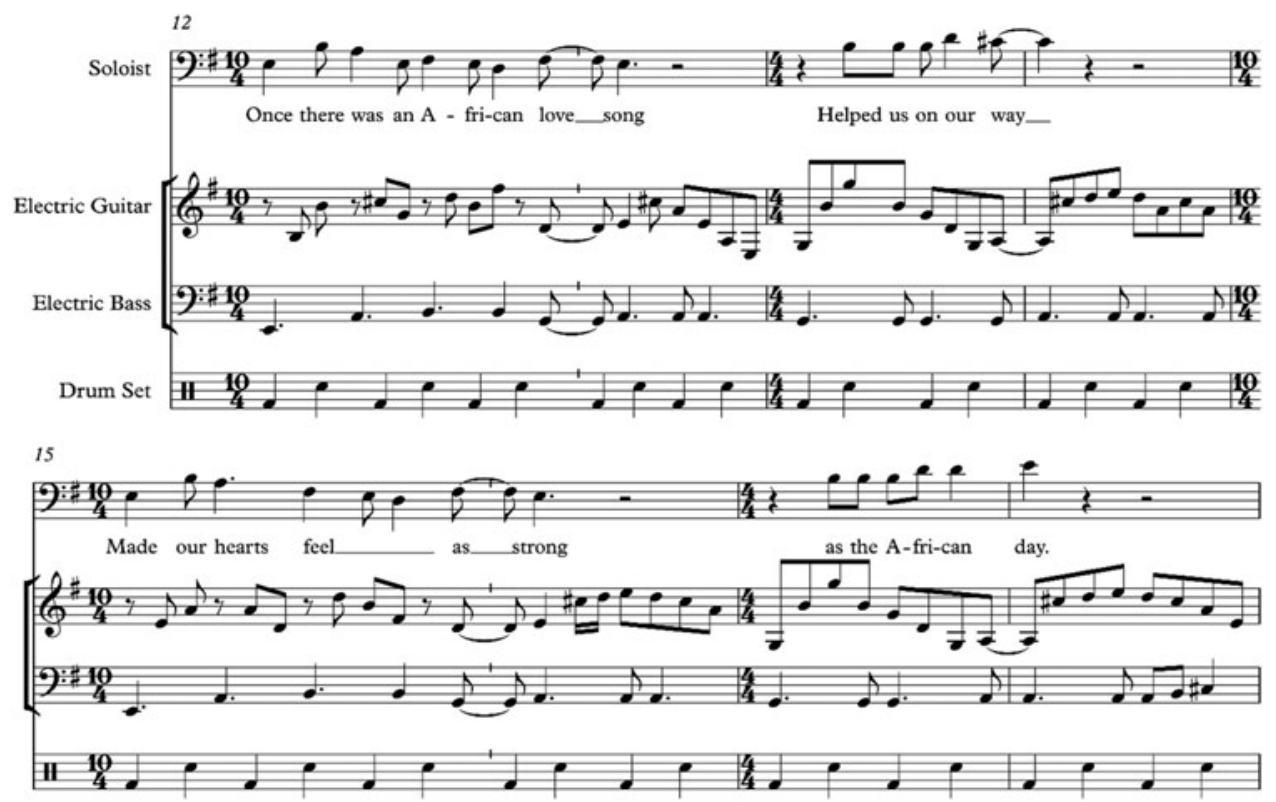

Example 2. Juluka, "December African Rain," pre-chorus. 
words 'love song' by syncopated crotchets. ${ }^{13} \mathrm{Mm} .13-14$ briefly provide a reorienting duple metre, and then the entire 18-beat cycle repeats again, with the same rhythmic profile largely preserved. 'December African Rain', then, involves a range of rhythmic and metric devices: shifting alignment between the call and response voices, hypermetrical extension and an unusual metre. I have not encountered these techniques in maskanda recordings, nor are they mentioned in scholarly writings on that genre. Consequently, Juluka's employment of these techniques appears to be an intentional decision to explore the artistic possibilities of joining Western compositional techniques together with maskanda practices. ${ }^{14}$

The formal organisation of 'December African Rain' is another respect in which the members of Juluka combine Western and Zulu musical ideas. The song begins by establishing a call-and-response texture, or ukubiza nokusabela, between the chorus and soloist. In a maskanda song, this call-and-response idea would usually form the basis for the rest of the piece's formal organisation; in 'December African Rain', by contrast, the call-and-response gives way to new material that suggests a pre-chorus and a chorus section. As we have already seen in our discussion of the 18-beat period, changes in instrumentation, vocal texture and metre all support hearing a formal division at $\mathrm{m}$. 12. The proper characterisation of the new formal section may not immediately be evident, but particularly when heard in relation to the next section, m. 12's doubled speed of the drumming and the large-scale pre-dominant to dominant harmonic progression build up a sense of momentum that is typical of pre-chorus sections (Summach 2011, §3; de Clercq 2012, p. 91). The subsequent appearance in $\mathrm{m} .18$ of the chorus section is unambiguous (see Example 3): in addition to the invariance of the lyrics in mm. 18-32 (Summach 2012, pp. 109-12) and the appearance of the song's title in the text, the music is also louder and texturally thicker than the preceding material, as is characteristic for chorus sections (de Clercq 2012, pp. 40-41). The pre-chorus's pre-dominant to dominant progression also leads to a pointed emphasis on the Ionian tonic at the start of the chorus, which is another common characteristic of chorus sections in Western popular music (de Clercq 2012, p. 50).

With these aspects of the song's formal organisation in mind, it is difficult to accept Ballantine's assertion that 'symbols for "black" [are] virtually relegated to the chorus'. In fact, with the exception of the backing singers' vocables, the chorus in 'December African Rain' appears to be its most conventionally Western section. For instance, at the start of chorus section all of the vocalists sing simultaneously, relating as a soloist and backup singers, in contrast to the verse's sustained call-and-response texture. Or consider the instrumentation: in the chorus section

13 This dotted-crochet pulse may be inspired by the rhythms of isiShameni dance (Clegg 1982, p. 11). The syncopation of the measure-ending crotchets, however, diminishes the similarity.

14 It is also possible, however, that the members of Juluka used unusual metre and hypermetre as a nod to Zulu bow songs: some of them contain phrase lengths of five and six measures, and at least one recorded song has an additive $2+3+3$ pulse organisation (see the songs performed by Princess Constance Magogo kaDinizulu and transcribed by David Rycroft, 1975/1976, pp. 65, 76-91). While it is perhaps unlikely that the members of Juluka knew the particular songs performed by kaDinizulu (or Rycroft's article, though Clegg could well have encountered it in his anthropological studies), they did know at least some traditional Zulu songs, as is evidenced by their inclusion of a war song with mouth-bow accompaniment as the final track of Universal Men. It is also worth noting that later moments in 'Sky', the next song to be discussed, also contain hypermetrical extensions: a fourmeasure melodic phrase is established by the chorus, followed by the soloist, but in subsequent repetitions it is occasionally expanded to encompass five and even six measures. 

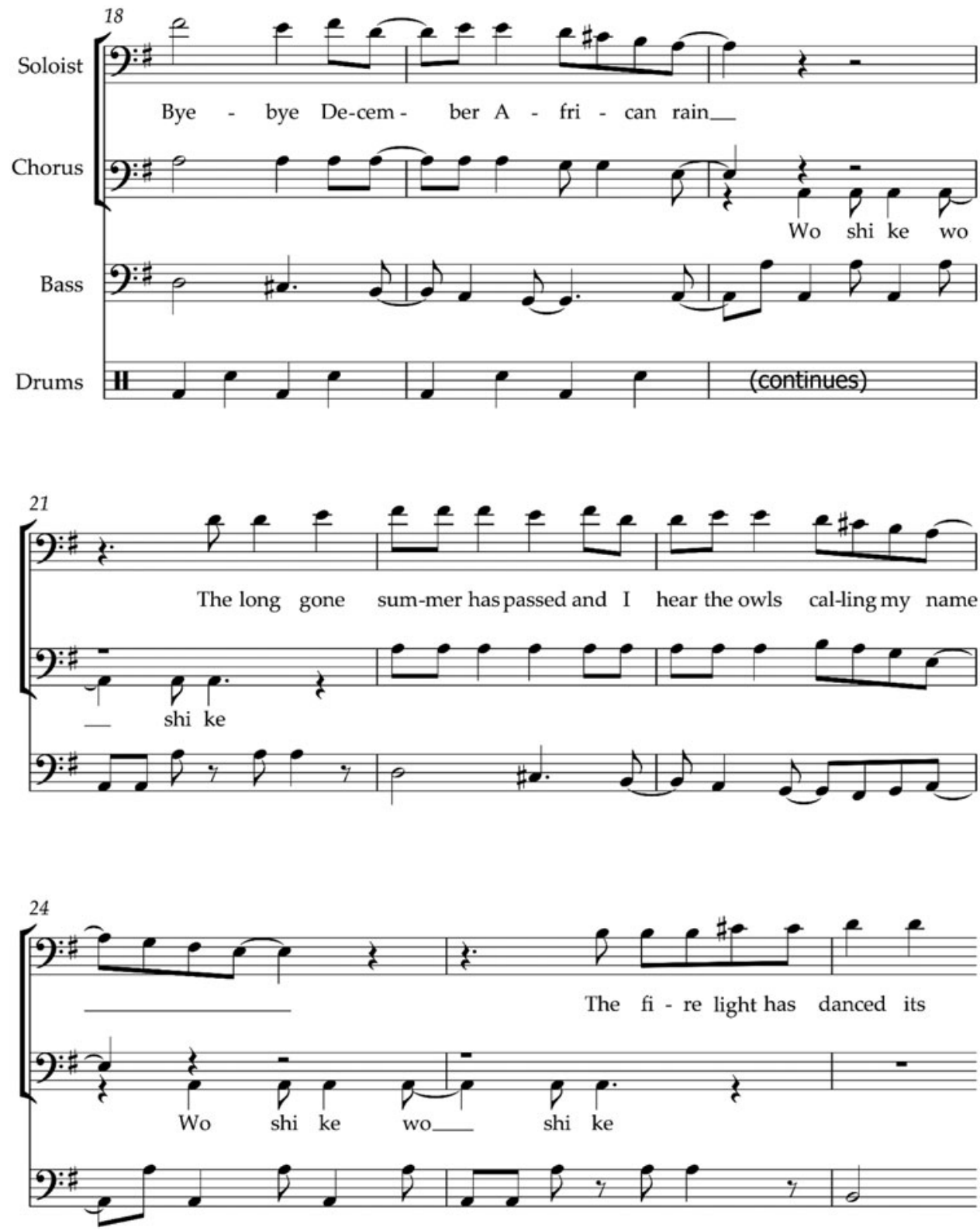

Example 3. Juluka, "December African Rain," beginning of chorus.

the previously prominent sound of the guitar recedes into the wash of the backing instruments. While this contributes to the greater textural fullness of the chorus, it also shifts away from the emphasis on guitar that 'distinctly flags the sound as South African in the World Music market and as a local production in the domestic [South African] market' (Meintjes 2003, p. 157). The song's harmonic schemes also support this impression: the verse's harmonic disposition in $\mathrm{mm}$. 3-11 somewhat suggests an isiZulu-style alternation between fundamentals of D and C, particularly in the synthesiser. The pre-chorus and chorus, in contrast, switch to an emphatically 
Western tonal syntax: leading tones replace the lowered-seventh scale degree throughout, half cadences abound and there is even an applied-dominant progression at mm. 40-41. As a result, the form, instrumentation and harmonies of 'December African Rain' clearly gainsay Ballantine's verse-chorus associations, and the textures and rhythmic features exhibit creative intermingling of Western and Zulu musical elements. Yet this style of verse/chorus-based song with strong maskanda influences was not Juluka's only model, as we shall now see.

\section{'Sky People'}

In 1979, some three years after Mchunu and Clegg formed Juluka, the band released its first album, Universal Men. The album's opening track, titled 'Sky People', proceeds in many ways as a maskanda song. For instance, the first 20 seconds of the piece are suggestive of an isihlabo introduction section (see Example 4). At the start a solo guitarist finger-picks a polyphonic texture which comprises two distinct melodic lines. The resulting music lays out the harmonic material that will govern the rest of the piece: C major and D minor triads, as is characteristic of the isiZulu subtype of maskanda. And finally, after the first 20 seconds, the end of the isihlabo is signalled by the entrance of other instruments, which establish a new 'melodic-rhythmic pattern', which they sustain through much of the rest of the piece.

Yet the opening 20 seconds of 'Sky People' also dispense with certain features of the isihlabo, such as its solo-guitar instrumentation. Instead, the guitar is joined by a chorus of male voices, which enters half-way through the introduction. The upper voices in this chorus sing a descending melody that loosely derives from the guitar part, and the lower voices mirror the upper ones, largely at the fifth below. The introduction's metrical disposition is also noteworthy: while solo-guitar isihlabo sections are unmetred, the introduction in 'Sky People' is clearly metrical, presumably to facilitate the coordination of guitarist and chorus. The guitarist starts a melodic descent every four crotchet beats, and every eight beats its melodic-rhythmic pattern repeats almost identically. Underlying this seemingly simple duple metre, however, is much more rhythmic complexity. For instance, although the chorus similarly starts a melodic descent every four crotchets, they are displaced by three semiquavers from the guitar's descents. (And this is not a matter of a simple semiquaver anticipation in the chorus's descents: the final note of their melodic figure is likewise displaced by three semiquavers from the end of the guitar's pattern.) Furthermore, the chorus repeats its melodic-rhythmic pattern every eight beats, just like the guitar, but their statements are staggered by one measure, with the guitar and chorus beginning their statements in alternate measures. Beginning a song with rhythmically complex relationships of this sort lessens the music's evocation of maskanda, with its unmetred isihlabo introductions.

The rhythmic complexity of the introduction of 'Sky People' also extends to its harmonic rhythm, which is entirely uncoordinated with the initiations of both the guitar's melodic descent and also the chorus's. Instead, as the lowest staves of Example 4's systems indicate, the chord roots never change on downbeats: in one measure $C$ enters on the third crotchet, ${ }^{15}$ and in the alternate measure the harmony

${ }^{15}$ Listening with this harmonic rhythm in mind can support an interpretation of the piece beginning on the third crotchet of an incomplete measure, in which case the harmonic shifts from D to C occur at beginnings of measures. 

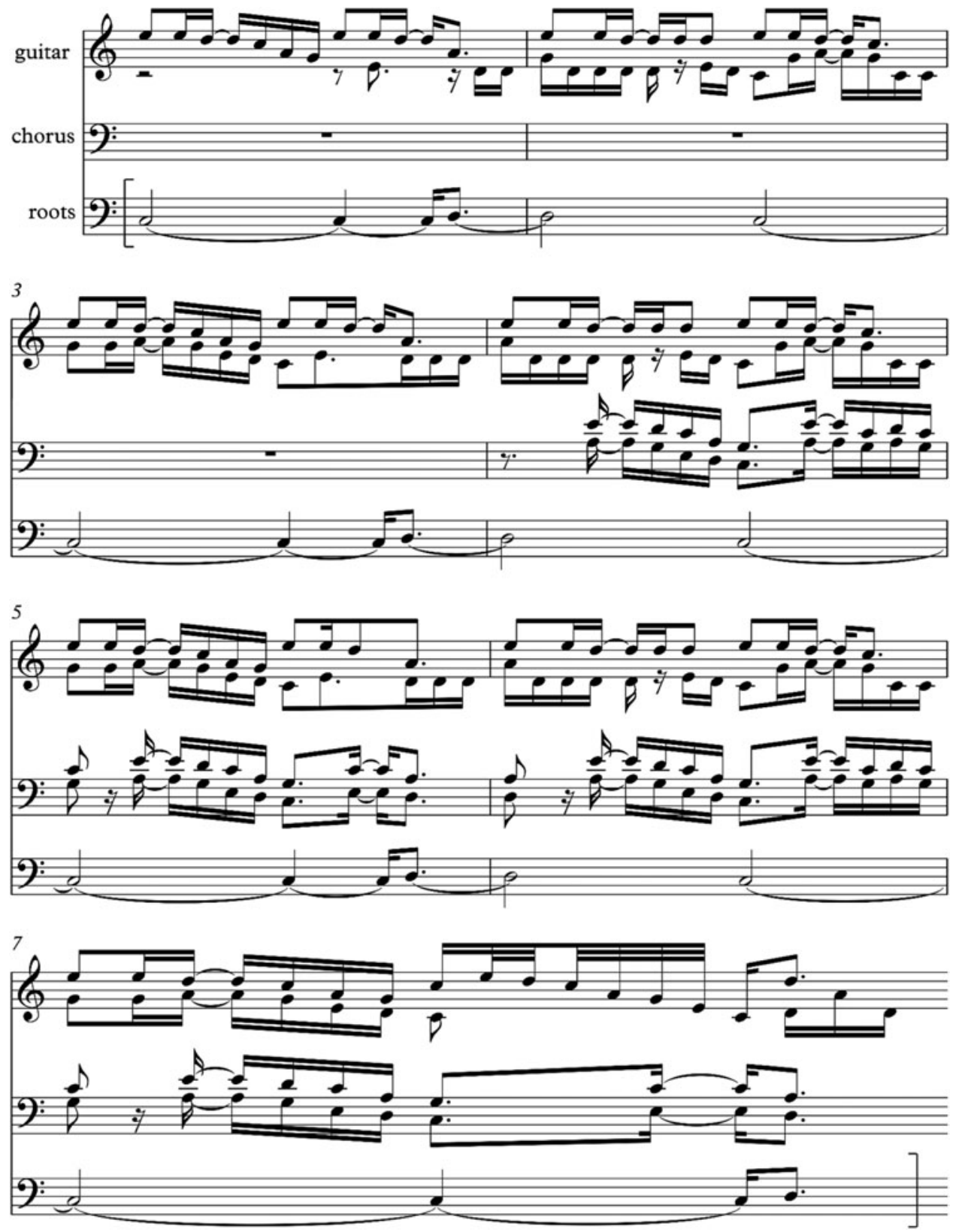

Example 4. Juluka, "Sky People," opening.

returns to $\mathrm{D}$ on the fourteenth semiquaver. This harmonic rhythm further aligns the song with maskanda music, where changes of harmony on weak beats are not uncommon, even at the level of weak semiquavers. ${ }^{16}$ Despite the metrical weakness of the

16 Although the secondary literature on maskanda does not identify this as a pattern, I have encountered many examples of maskanda recordings featuring changes of harmony that fall on weak crotchets and 
latter harmonic shift, it is reinforced by its concurrence with the last note of the guitar's higher melodic line and by the clear change of harmony in the chorus's parts.

The change of harmony on the fourteenth semiquaver of the even-numbered measures also relates to one of the song's most intriguing features. In addition to all their metrical complexity, the first 20 seconds of 'Sky People' are also in a state of metrical displacement from the rest of the song. The seam between the end of the would-be isihlabo and the start of the next section is unmistakable: the guitar breaks its pattern and establishes the new melodic-rhythmic pattern that it sustains for most of the song thereafter. Two measures later, the bass and drums enter, buttressing the duple metre that persists until the end. Yet this seam is irreconcilable with the duple metre established in the introduction. As Example 5 shows, the change occurs on what would be the fourteenth semiquaver in $\mathrm{m}$. 8 (at the same point where the harmonic shift was expected to fall), but this moment instead becomes the downbeat of a new measure, as the entrance of the bass and drums eight beats later retrospectively confirms. Since the point of metric reinterpretation is such a weak beat in the original metre - a weak semiquaver - it is very difficult to hear any sense of metrical continuity between the introduction and the piece's continuation. Instead, one can understand the introduction's metrical disjointedness as an analogy for the isihlabo's lack of metre.

Two further features of the later sections of 'Sky People' merit discussion. First is the rhythmic character of the melodic patterns established by the instruments after m. 9. While the bass drum sets out an unmistakable crotchet pulse beginning in $\mathrm{m} .11$, the guitar, snare drum and bass line all cultivate a cross-rhythm of four dotted quavers followed by two regular quavers. Moreover, the harmonic rhythm also aligns with this cross-rhythm: the new melodic-rhythmic pattern's harmonic support shifts from $D$ to $C$ on the tenth semiquaver of each bar, simultaneously with the fourth dotted quaver. This sort of cross-rhythm 'performs Zuluness', as Meintjes (2003, p. $174 \mathrm{ff}$.) puts it, through its resemblance to the $3+3+2$ rhythm that structures various Isishameni dance steps (Clegg 1982, p. 11).

The other noteworthy feature is the bass's imposition of Western functionalharmony connotations onto the piece's isiZulu-based harmonic language. When the chorus begins singing its four-measure phrases in $\mathrm{m}$. 14, the bass player establishes a new melodic pattern that he then varies freely. The characteristically isiZulu harmonic material of two triads with fundamentals a whole tone apart (D minor and C major triads in this song) is still plainly evident, particularly on beats one and four. Yet the bass line always includes a prominent A towards the end of beat four, despite the fact that this emphasised note is not a member of the underlying C major triad. Instead, the bass line presents a blending of harmonic implications: the addition of the non-triadic $A$ to the $C$ harmony suggests a

quavers. For a few examples, see Shiyani Ngcobo, 'Wayi Thathaphi', from Introducing Shiyani Ngcobo, Phuzekhemisi, 'Sinkhumbule' Khaya', from Bayede Zulu, and Phuzushukela, 'Shomi Yami', from Iqoma Kandabula. The origins of this tendency may lie in bow songs, since Rycroft's transcriptions show many changes of harmony at mid-points of notated measures (1975/1976, pp. 76-91); additionally, an umakhweyana song performed by Trizinah Dlamini features a harmonic pattern that twice changes harmony on weak quavers ('Ubalwana lwami', from Zulu Songs from South Africa). On the other hand, harmonic shifts do not appear on beats weaker than that in Rycroft's transcriptions, so the harmonic rhythms of isiZulu may in fact derive from another source. 

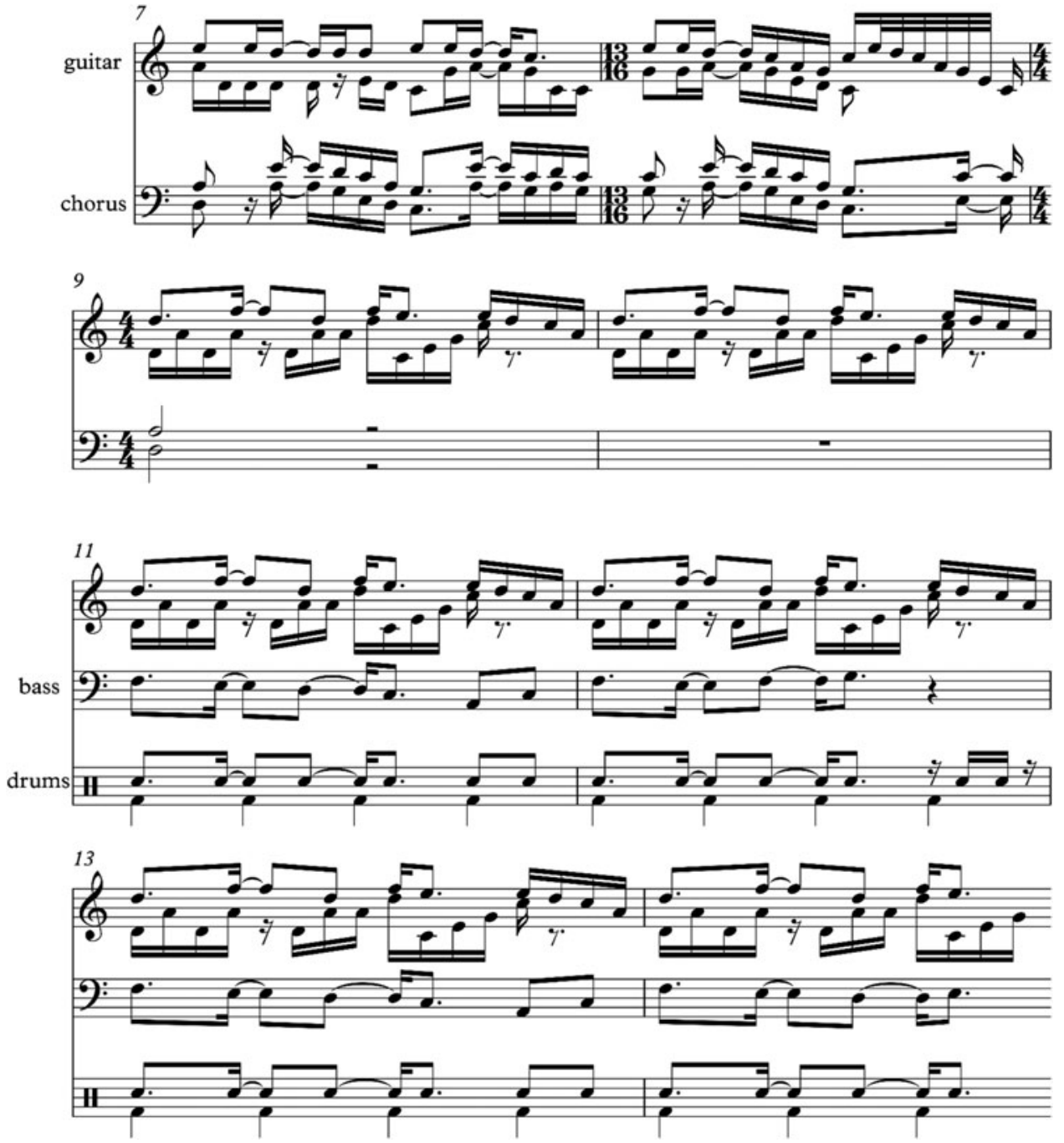

Example 5. Juluka, "Sky People," continuation.

tonic-dominant opposition (although a minor dominant chord, to be sure) simultaneously with the whole-tone-related fundamentals from isiZulu maskanda music.

In sum, 'Sky People' presents a sophisticated mediation of Western and Zulu musical patterns. The introduction's guitar figuration suggests an isihlabo section, but the characteristic lack of metre is replaced by a state of metric shiftedness. When the chorus enters and lessens the evocation of an isihlabo, their call-andresponse patterns still signal Zuluness through their metrically off-set arrangement. Thereafter, the harmonic materials conform to the two-root patterns found in isiZulu songs, but the bass player consistently adds a non-triadic note that suggests Western tonic-dominant relations. In doing so, Juluka presents a musical argument that a rich aesthetic experience can result from breaching the strict cultural segregation which the apartheid regime sought to impose. 


\section{'Scatterlings of Africa'}

The final song is probably Juluka's best-known composition. 'Scatterlings of Africa', first released on their 1982 album Scatterlings, appeared on the soundtrack for the film Rainman and made the UK singles chart, although in an arranged form recorded by Savuka, Johnny Clegg's second band. ${ }^{17}$ In contrast to the previous two songs examined, the lyrics of 'Scatterlings of Africa' directly critique the Apartheid ideology. Rather than subscribing to the dogma of an essential difference between races, the members of Juluka emphasise all of humanity's common origin in Africa and our shared journey, singing that 'we are scatterlings of Africa, both you and I. We're on the road to Phelamanga, beneath this copper sky'. ('Phelamanga' is a coined word roughly meaning 'the end of lies'. ${ }^{18}$ )

This song hews less closely to the characteristics of maskanda than the previous songs considered, but it still preserves many of their sonic signatures. Like 'Sky People', the song's introduction features the male chorus singing in two parts, at roughly a fifth from each other, and then a brief instrumental section (of guitar, bass, and drums) before the main vocal melody begins. And like 'December African Rain', the song draws upon Western tonal syntax and harmonic progressions, presents a modified verse-chorus structure and contains a significant amount of rhythmic complexity, which will be our focus.

In the introduction of 'Scatterlings of Africa', the bass drum begins to articulate a steady four-on-the-floor crotchet pulse, and the other instruments and singers clearly establish four-beat groupings of that pulse (Example 6). As a result, listeners are primed to hear a four-four metre, and they may well continue to hear the music that way until the last measure of the verse. Yet as the instrumental lead-in to the first verse begins in $\mathrm{m} .9$, listeners are gradually confronted with challenges to that interpretation. The guitar and bass join together to play a varying melodic figure that repeats every eight beats, and the soloist's melody also begins a new line every eight beats, as Example 7 demonstrates. Consequently, listeners hearing a four-four metre receive confirmation of that interpretation every two measures. The downbeats of the weaker four-four measures, however, are much harder to hear, since the soloist and bass player avoid playing at those moments. Instead, I prefer to hear a three-plus-five division of the eight-beat period, as shown in staff $b$ of Example 7. In this interpretation the new mid-period division is supported by a contour accent in the vocal line and the onset of a relatively long duration in the bass part. Thereafter the bass line is entirely syncopated, but the guitar melody suggests a division of three-plus-two crotchets.

Latent beneath the bass drum's crotchet pulse, however, lies yet another rhythmic stream. In fact, the guitar, bass, and soloist project a dotted-crotchet pulse through much of the eight-beat period (see staff c of Example 7). Admittedly, this pulse is not so easy to entrain, because it both conflicts with the percussion and breaks off in favour of simple crotchets for the last two beats of each period. (It does, however, become clearer in the chorus section, where the bass plays dotted crotchets at the start of nearly every measure.) This alternate pulse has implications

17 Savuka's version appeared on their album Third World Child (1987), and reached 75 on the UK Singles Chart in May 1987 (https:/www.officialcharts.com/charts/singles-chart/19870510/7501/, accessed 5 August 5 2019).

${ }^{18}$ https://www.phelamanga.co.za/let-s-talk/10-what-s-in-a-name (accessed 5 August 2019). 


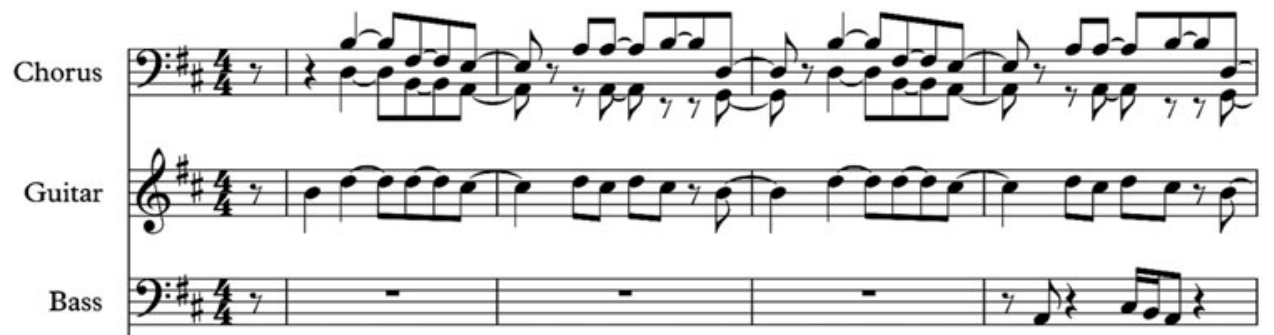

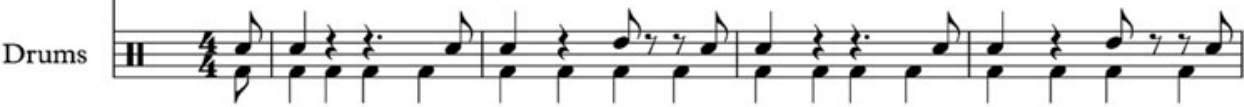

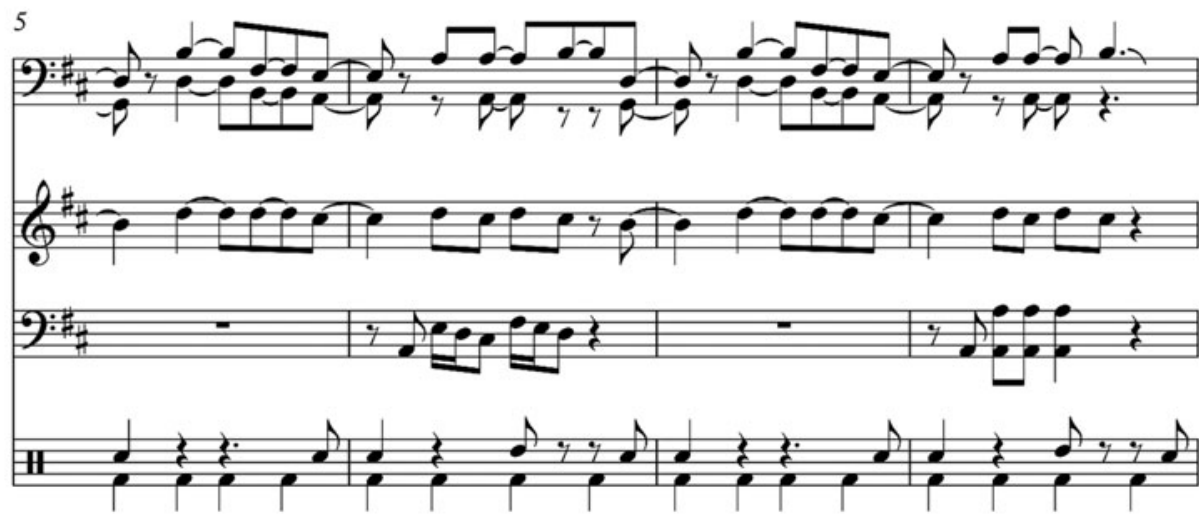

Example 6. Juluka, "Scatterlings of Africa," opening.

11

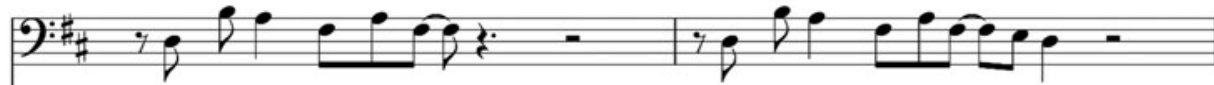

Cop-per sun sin-king low

Scat-ter-ling and fu-gi - tives

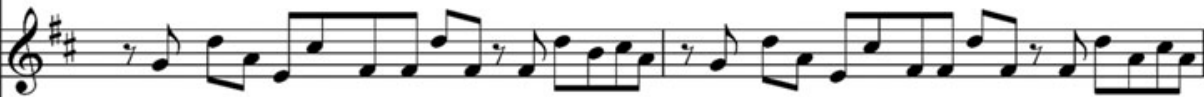

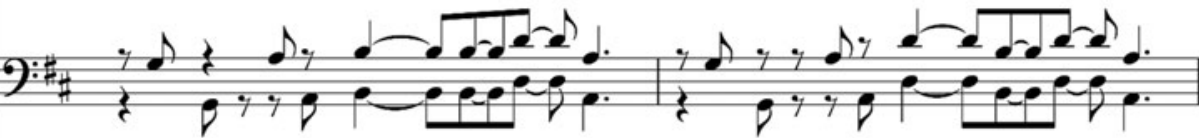

$\sqrt{x+x} \sqrt{x+x} \sqrt{x+x} \sqrt{x+x} \sqrt{x+x} \times \sqrt{x+x} \sqrt{x+x} \sqrt{x+x}$

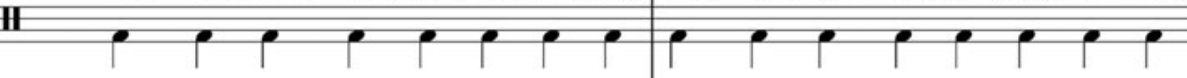

a. $11 \quad 40$

b.

$113+5$ d.

c. $\quad 116$.

Example 7. Juluka, "Scatterlings of Africa," beginning of first verse. 
for the song's text setting. For one, because the soloist is articulating a pulse that is not isochronous with the underlying crotchet pulse, notes that the soloist emphasises often fall on weak beats of the overall metric framework. Furthermore, melodic and rhythmic factors frequently accentuate weak syllables of the lyrics. For instance, in the text's first line, 'Copper sun, sinking low', the second syllables of 'copper' and 'sinking' are the highest pitches in their respective melodic contours and align with the bass drum's crotchet pulse, despite being unstressed syllables from a poetic perspective. This seeming lack of artfulness, however, is actually a hallmark of Zulu song. As Rycroft has noted, Zulu singers appear to favour 'extreme forms of word distortion regarding syllable length and stress placement. ... In song, the duration given to the longer and shorter syllables of spoken Zulu is frequently directly reversed, and stressed syllables are placed on off-beats' $(1971,237)$. As a result, Juluka's decision to set the lyrics to a conflicting pulse stream was an effective way both to ensure a degree of internal coherence for the melodic line, and to align the setting of English lyrics with Zulu song practices.

Although the chorus section (see Example 8) does clarify the dotted-crotchet pulse, it further complicates the song's metric profile by shifting to a repeated pattern lasting seven crotchet beats, which the bass drum continues to articulate. ${ }^{19}$ Curiously, Johnny Clegg did not view the seven-beat periodicity as a necessary feature of the chorus. When he re-recorded the song five years later with Savuka, an extra beat was added to the end of each seven-beat period to render a consistent duple metre. ${ }^{20}$ I suspect that this alteration was made to support the more rock-oriented sound of Savuka. In particular, the drummer in the Savuka recording plays a conventional pattern of snare drum hits every second crotchet (offbeat) throughout, and this pattern would have become misaligned with the metre every second measure had the seven-four metre been maintained. (The drum pattern alone does not explain everything, however, since Clegg also performed the duplemetre version even when no drumming was present. ${ }^{21}$ ) With Savuka, Clegg moved away from Juluka's focus on Zulu-signifying sounds towards a more pan-African style (Meintjes 2017, p. 160), so it is possible that he viewed the sevenfour metre as a Zulu-connoting peculiarity that was less suitable for his new band's purview. ${ }^{22}$

The second verse of 'Scatterlings of Africa' exhibits additional metrical manipulations that may support the association of irregular metrical frameworks with the performance of Zuluness. Once the chorus section concludes, the instrumental lead-in from m. 9 returns, followed by new words set to a slight modification of the first verse's melody. Throughout these measures the rhythms and pulses of the first verse are maintained. The chorus section, however, does not immediately follow; instead, the second verse continues on to become twice the length of the

19 The internal division of these seven beats is somewhat inconsistent: the soloist, bass and organ do articulate the dotted-crotchet pulse at the start of each measure, but the endings alternate between a pattern of crotchet, dotted crotchet and one of two crotchets.

20 The Savuka version was released only a year after Juluka's The Good Hope Concerts album, whose version of 'Scatterlings of Africa' still has the seven-beat periods. Meintjes contrasts many details of the Juluka and Savuka versions of this song, but gives no indication of having noticed the changed metre (2017, pp. 161-2).

21 Johnny Clegg, interview with Azania Mosaka and performance on Radio 702, 26 May 2017 (https:// youtu.be/pcx3fYo4bN0, 25:00; accessed 12 August 2019).

22 Concerning the possible Zulu connotations of unusual metric and rhythmic patterns, see footnote 14 . 

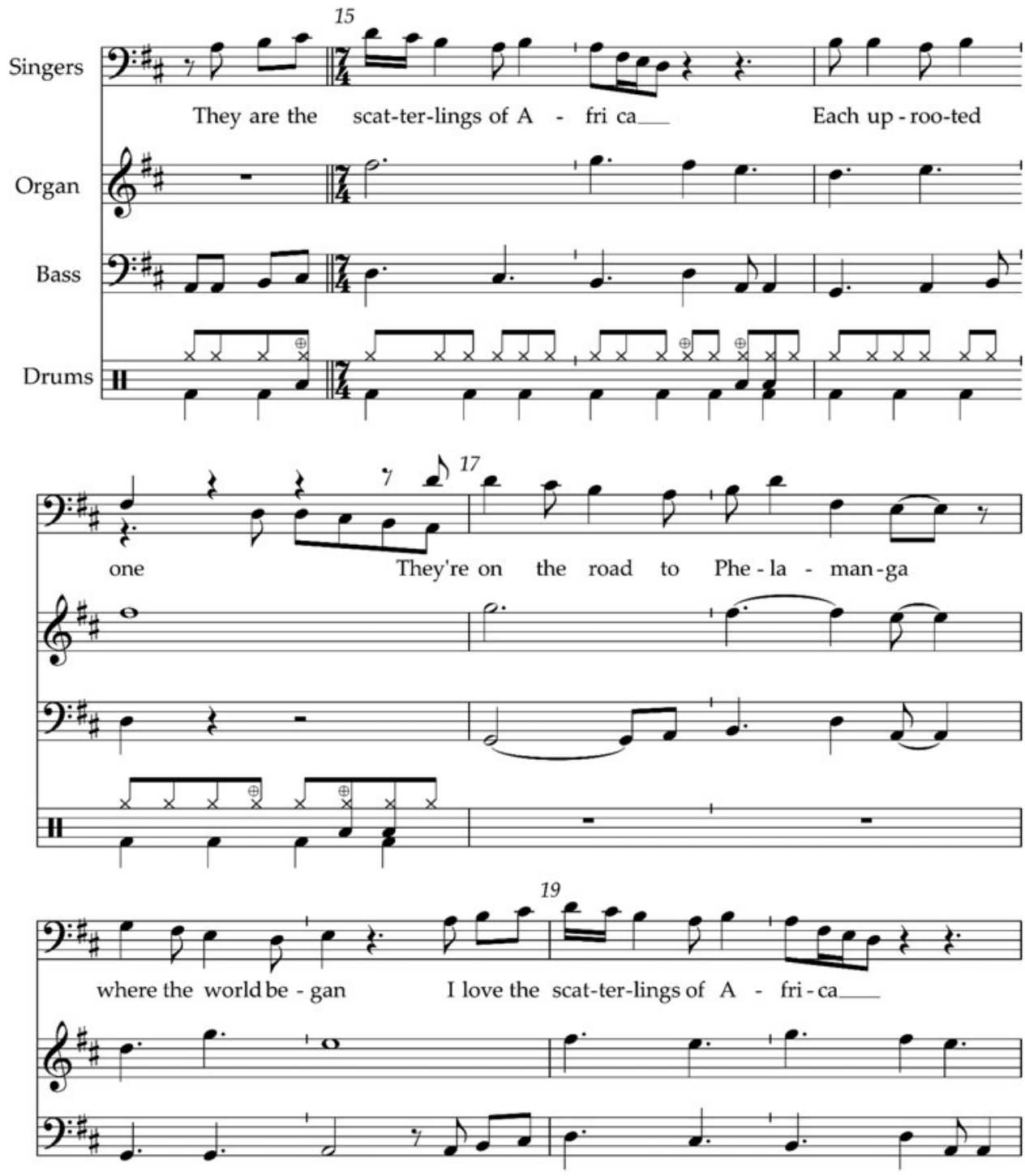

Example 8. Juluka, "Scatterlings of Africa," beginning of chorus.

first verse. ${ }^{23}$ The new, second part of the second verse (Example 9) differs in notable ways from the first half. From a metrical perspective, any hint of a dotted-crotchet pulse is suppressed. Although the interiors of the eight-beat periods are still quite syncopated, the effect is of a syncopated four-four metre, rather than the more complicated three-plus-five of the verse's beginning. With respect to the lyrics, the verse's second half directly repeats its words: 'African ideals, make the future clear'. Note

23 Since the second verse and the chorus both last eight seven- or eight-beat periods, this suggests that the first verse is better heard as a half-length verse, since it is only four periods long. What I call the second half of the second verse sounds more relaxed than the first half, so I am not inclined to interpret it as a pre-chorus. 


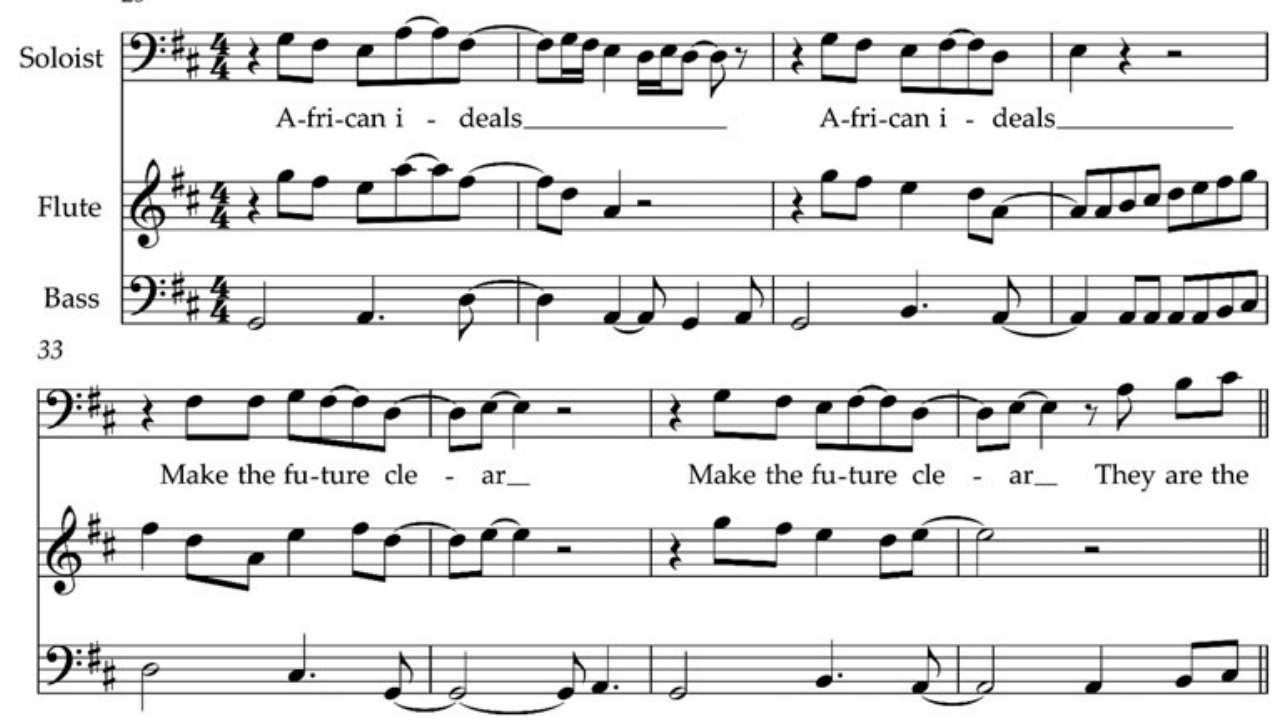

Example 9. Juluka, "Scatterlings of Africa," conclusion of second verse.

that it is when Juluka invokes the implicit pan-Africanness of 'African ideals' that they shift from the idiosyncratic complex metrical state to a more conventional duple metre. (The verse's second half also introduces an accompanying flute, an instrument which is not strongly associated with Zulu musical culture. ${ }^{24}$ ) This interpretative association of complex metre with performing Zuluness is speculative, not certain, particularly since most of Juluka's songs are in conventional duple metres, but it does offer possible insight into the metrical changes over the course of the 'Scatterlings of Africa' and across different performances of it.

\section{Conclusion}

The members of Juluka worked together across lines of race and culture, and in doing so demonstrated possibilities for artistic and interpersonal richness that the apartheid regime sought to deny. Their songs present a mediation of Western and Zulu musical cultures, and, pace Ballantine, their musical integrations were far from awkwardly worked. With its methodology of closely analysing harmony, form and rhythm, this essay has demonstrated that their songs far surpass the binary, one-or-the-other oppositions of 'white' and 'black' symbols which Ballantine ascribes to them. For instance, in 'Sky People' and the verse of 'December African Rain', the harmonic organisations suggest a superimposed Western tonic-dominant relation on top of isiZulu-based pairs of chordal roots separated by a tone or semitone. Nor are the

24 Rycroft does note that solo flute playing 'was formerly very common' in traditional Zulu practice (1977, 224), but the use of the flute by Zulu musicians appears to be quite rare in recordings of Zulu music. Furthermore, this apparent association of the flute and pan-Africanness occurs in another Juluka song: in 'Deliwe', from Universal Men, the flute only plays during a formal section whose lyrics begin with 'You are a child of Africa'. 
Zulu-signifying elements virtually relegated to the choruses. The verse in 'December African Rain' exhibits far more textural and harmonic signs of maskanda music than does its chorus, and 'Sky People' entirely dispenses with verse-chorus form in favour of a maskanda song structure. Finally, in 'Scatterlings of Africa' and 'December African Rain', Juluka's use of unusual time signatures, complex rhythmic patterns, and hypermetrical manipulations resemble both Western compositional practices and the rhythmic and metric patterns of Zulu ngoma dance and bow songs.

Why does it matter that Juluka's transcultural collaboration resulted in successful musical integrations? The stakes are larger than merely correcting the scholarly record, or even defending the aesthetic value of the band's music against dismissive judgement. Rather, as Byerly (1998, pp. 23-6) has pointed out, the existence of bands which exhibited 'a complete fusion of musicians, styles and languages from different backgrounds' and whose works were 'characterized by rich superimpositions of not merely musical components like melodies, harmonies, rhythms, and instrumentations, but also by juxtapositions of linguistic components' was an important strategy for interracial collaboration during the democratisation process. In this light, the artistic success of Juluka's blendings of Western and Zulu musical ideas directly contributes to the potency of their artistic activism. Through their songs they demonstrated that working together across lines of imposed cultural separation creates a richer world, that 'something else is possible' beyond apartheid. Consequently, musical analysis of Juluka's songs not only brings to light their overlooked artistry, but also helps us to appreciate better their music's role in advocating for a more just and united world.

\section{Acknowledgement}

I would like to express my gratitude to my two anonymous reviewers for their very helpful suggestions.

\section{References}

Baines, G. 2008. 'Popular music and negotiating whiteness in Apartheid South Africa', in Composing Apartheid: Music for and against Apartheid, ed. G. Olwage (Johannesburg, Wits University Press), pp. 99-113

Ballantine, C. 2004. 'Re-thinking "whiteness"? Identity, change, and "white" popular music in post-Apartheid South Africa', Popular Music, 23/2, pp. 105-31

Byerly, I.B. 1998. 'Mirror, mediator, and prophet: the music Indaba of late-Apartheid South Africa', Ethnomusicology, 42/1, pp. 1-44

Clegg, J. 1982. 'Towards an understanding of African dance: the Zulu Isishameni style', in 2nd Symposium on Ethnomusicology, ed. A. Tracey (Grahamstown, ILAM), pp. 8-14

Clegg, J. 2017. Interview by B. Bambury. Day 6, CBC, 24 November 24. https://www.cbc.ca/radio/day6/episode365-trump-s-accusers-monstrous-art-swearing-is-good-humanizing-the-homeless-johnny-clegg-andmore-1.4413752/goodbye-is-a-tough-thing-groundbreaking-south-african-superstar-johnny-clegg-sings-farewell-1.4413761

Clegg, J., and Drewett, M. 2006. 'Why don't you sing about the leaves and the dreams? Reflecting on music censorship in Apartheid South Africa', in Popular Music Censorship in Africa, ed. M. Drewett and M. Cloonan (Aldershot, Ashgate), pp. 127-36

Collins, T. 2006/2007. 'Constructing Maskanda', SAMUS: South African Music Studies, 26-27, pp. 1-26

Davies, N. 1994. 'The guitar in Zulu Maskanda tradition', The World of Music, 37/2, pp. 118-37

de Clercq, T. 2012. 'Sections and successions in successful songs: a prototype approach to form in rock music', $\mathrm{PhD}$ dissertation, University of Rochester

Drewett, M. 2005. " Stop this filth": the censorship of Roger Lucey's music in Apartheid South Africa', SAMUS: South African Journal of Musicology, 25, pp. 49-65 
Eyerman, R., and Jamison, A. 1998. Music and Social Movements: Mobilizing Traditions in the Twentieth Century (Cambridge, Cambridge University Press)

Gunner, E. 1990. 'Wand or walking stick? The formula and its use in Zulu praise poems', in The Oral Performance in Africa, ed. I. Okpewho (Ibadan, Nigeria, Spectrum Books), pp. 185-207

Meintjes, L. 2003. Sound of Africa!: Making Music Zulu in a South African Studio (Durham, NC, Duke University Press)

Meintjes, L. 2017. Dust of the Zulu: Ngoma Aesthetics after Apartheid (Durham, NC, Duke University Press)

Muller, C.A. 2008. Focus: Music of South Africa, 2nd edn (New York, Routledge)

Ngcobo, N. 1982. 'Glimpses into South Africa - a perspective through Juluka music', Reality 14/1, pp. 4-6

Olsen, K. 2014. Music and Social Change in South Africa: Maskanda Past and Present (Philadelphia, PA, Temple University Press)

Pooley, T.M. 2016. 'Umaskandi izibongo: semantic, prosodic and musical dimensions of voice in Zulu popular praises', African Music 10/2, pp. 7-34

Rycroft, D.K. 1962. 'Zulu and Xhosa praise-poetry and song', African Music 3/1, pp. 79-85

Rycroft, D.K. 1971. 'Stylistic evidence in Nguni song', in Essays on Music and History in Africa, ed. K. Wachsmann (Evanston, Northwestern University Press), pp. 213-41

Rycroft, D.K. 1975/76. 'The Zulu bow songs of Princess Magogo', African Music 5/4, pp. 41-97

Rycroft, D.K. 1977. 'Evidence of stylistic continuity in Zulu "town" music', in Essays for a Humanist: An Offering to Klaus Wachsmann (Spring Valley, NY, Town House Press), pp. 216-60

Solis, G. 2012. 'Thoughts on an interdiscipline: music theory, analysis, and social theory in ethnomusicology', Ethnomusicology 56/3, pp. 530-54

Summach, J. 2011. 'The structure, function and genesis of the prechorus', Music Theory Online 17/3

Summach, J. 2012. 'Form in top-20 rock music, 1955-89', PhD dissertation, Yale University

Titus, B. 2013. "Walking like a crab": analyzing Maskanda music in post-Apartheid South Africa', Ethnomusicology, 57/2, pp. 286-310

\section{Discography}

Juluka, 'Sky People', Universal Men. CBS, DNW 2429. 1979

Juluka, 'Scatterlings of Africa', Scatterlings. MINC, 1040. 1982

Juluka, 'December African Rain', Work for All. MINC, 1070. 1983

Phuzushukela, 'Shomi Yami', Iqoma Kandabula. Gallo. 1993

Phuzekhemisi, 'Sinkhumbule' Khaya', Bayede Zulu. Gallo. 2012

Shiyani Ngcobo, 'Wayi Thathaphi', Introducing Shiyani Ngcobo. World Music Network, INTRO101. 2004

Trizinah Dlamini, 'Ubalwana lwami', Zulu Songs from South Africa. Lyrichord, LLST 7401. [1986] 